\title{
A Methanolic Extract of Ocimum basilicum Exhibits Antioxidant Effects and Prevents Selenite-induced Cataract Formation in Cultured Lenses of Wistar Rats
}

\author{
Thiraviyam Anand', Mahalingam Sundararajan ', Muniyandi Anbukkarasi', Philip Aloysius Thomas ${ }^{2}$, \\ Pitchairaj Geraldine ${ }^{1, *}$
}

\section{Thiraviyam Anand', Mahalingam Sundararajan', Muniyandi Anbukkarasi ${ }^{1}$, Philip Aloysius Thomas ${ }^{2}$, Pitchairaj Geraldine ${ }^{1, *}$}

\section{'Department of Animal Science,} School of Life Sciences, Bharathidasan University, Tiruchirappalli-620024, Tamil Nadu, INDIA.

${ }^{2}$ Department of Ocular Microbiology, Institute of Ophthalmology, Joseph Eye Hospital, Tiruchirappalli-620024, Tamil Nadu, INDIA.

\section{Correspondence}

Prof. Pitchairaj Geraldine

UGC-BSR Faculty Fellow, Department of Animal Science, School of Life Sciences, Bharathidasan University,

Tiruchirappalli- 620 024, Tamil Nadu, INDIA.

Phone no : +0431- 2407040

E-mail: gerryarchup@yahoo.co.in

History

- Submission Date: 06-11-2018;

- Review completed: 03-01-2019;

- Accepted Date: 11-04-2019

DOI : 10.5530/pj.2019.11.79

Article Available online

http://www.phcogj.com/v11/i3

\section{Copyright}

(C) 2019 Pharmacognosy Journal. This is an open-access article distributed under the terms of the Creative Commons Attribution 4.0 International license.

\begin{abstract}
Objective: An extract (Methanolic) of the Ocimum basilicum leaf was analysed for potential to abrogate experimental formation of cataract in-vitro. Methods: Phytoconstituents were first detected in $O$. basilicum extracts (Aqueous or methanolic) by gas chromatographic-mass spectrometric analysis. The putative antioxidant activity of these extracts was then assessed by measuring in-vitro radical-scavenging activity, ion-chelating potential and reducing potency. Potential cytotoxicity of the extract on Human lenticular epithelial B3 (HLE-B3) cells was also sought. Finally, possible prevention of cataract formation by the methanolic extract was gauged in selenite-exposed lenses obtained from Wistar rats. There were 3 groups (8 Lenses in each): Group I (Lenses incubated in Dulbecco's modified Eagle's medium [DMEM] alone); Group II (Lenses incubated in DMEM with sodium selenite [100 $\mathrm{MM} / \mathrm{ml}]$ ); Group III (Lenses incubated in DMEM with selenite $[100 \mu \mathrm{M} / \mathrm{ml}]$ and the 0 . basilicum methanolic extract $(200 \mu \mathrm{g} / \mathrm{ml}$ DMEM). Gross lenticular morphology was assessed. Levels of lenticular malondialdehyde (MDA) and reduced glutathione (GSH) were also measured. Results: A higher intensity of antioxidative activity was noted in the methanolic extract than in the aqueous extract. The methanolic extract exhibited negligible cytotoxicity. On morphological examination, marked opacification was seen in all 8 Group II lenses whereas there was no opacification in 7 of 8 Group III lenses. Near normal mean levels of reduced glutathione and malondialdehyde, were noted within Group III lenses. Conclusion: The methanolic extract of the 0 . basilicum leaf appears to prevent selenite-induced cataract formation in-vitro.
\end{abstract}

Key words: Ocimum basilicum, Phytoconstituents, Oxidative stress, Antioxidants, Cataract, Crystallins.

\section{INTRODUCTION}

Cataract formation, in which the ocular lens becomes opacified, is the principal aetiology of blindness worldwide; $51 \%$ of preventable blindness possibly involves cataract. ${ }^{1}$ In India, cataract reportedly accounts for $50-80 \%$ of the bilaterally-blind. ${ }^{2}$ Currently, removal of the cataractous lens (By various surgical techniques) followed by intraocular placement of a synthetic lens constitutes the universally-accepted method to manage this condition. ${ }^{3}$

Lenticular opacification is postulated as a consequence of oxidative stress. ${ }^{4}$ Following photochemical formation of Reactive Oxygen Species (ROS) within the lens and aqueous humour, there is oxidative damage to lenticular tissue. ${ }^{5}$ Oxidative stress possibly induces cataractogenesis by bringing about several changes, such as massive oxidation of thiol to both protein and mixed disulfides, ${ }^{6}$ decreasing density of lenticular epithelial cells and levels of Soluble Sulfhydryls (S-SH) and depleting cellular antioxidants. ${ }^{7}$ Further, the induction of a pro-oxidant environment of the lens leads to abnormal accumulation of lenticular calcium, resulting in proteolysis of lenticular crystallins by activation of calpain isoforms. ${ }^{8}$

Supplementing a diet with antioxidant-rich biocompounds reportedly maintains lenticular antioxidant status at normal levels while shielding cells from oxidative damage. ${ }^{9}$ Antioxidants from natural sources, rather than synthetic antioxidants, are preferred for use. ${ }^{10}$ Antioxidant-replete plant extracts which reportedly exhibit anticataractogenic potential include Pleurotus ostreatus (Oyster mushroom), ${ }^{11}$ Ocimum sanctum, ${ }^{12}$ Vitex negundo, ${ }^{13}$ Cineraria maritima,${ }^{14}$ Aegle marmelos,${ }^{15}$ Tabernaemontana divaricata ${ }^{16}$ and Leucas aspera. ${ }^{17}$ Crude extracts of medicinal herbs are possibly more biologicallyactive than are purified compounds..$^{18}$ Mazandarani et al. have reported that solvent polarity in an extract possibly enhances efficacy of its polyphenol constituents, which represent a copious reserve of antioxidants. ${ }^{19}$ The solvent system and extraction method

Cite this article: Anand T, Sundararajan M, Anbukkarasi M, Thomas PA, Geraldine P. A Methanolic Extract of Ocimum basilicum Exhibits Antioxidant Effects and Prevents Selenite-Induced Cataract Formation in Cultured Lenses of Wistar Rats. Pharmacog J. 2019;11(3):496-504. 
used also influence the antioxidant yield. ${ }^{20}$ Aqueous, ethanol, acetone and methanol are extensively used as solvents to recover plant constituents. ${ }^{21}$

Ocimum basilicum (O. basilicum), a member of family Lamiaceae, is a kitchen herb. It also serves as a traditional Indian remedy ${ }^{22}$ for certain disorders, including cough, inflammation, dyspepsia, aches, pains and eye diseases. ${ }^{23,24}$ O. basilicum reportedly possesses hypolipidemic, ${ }^{25}$ antiinflammatory ${ }^{26}$ and anti-hyperglycemic ${ }^{27}$ activity. O. basilicum is also documented to be a copious source of antioxidants. ${ }^{28,29}$

Using Gas Chromatographic-Mass Spectrometric (GC-MS) analysis, we sought phytoconstituents within a methanolic extract and an aqueous extract of the leaf of $O$. basilicum. Following this, we assessed possible in-vitro antioxidative activity of these extracts. Based on its perceived superior efficacy, the methanolic extract was chosen to undergo assessment as a potential anticataractogenic agent in an experimental (in-vitro) setting of selenite-induced formation of cataract in lenses surgically removed from the eyes of Wistar rats.

\section{MATERIALS AND METHODS}

\section{Chemicals and solvents}

Sodium selenite was purchased from LOBA Chemie (Mumbai, India). Dulbecco's modified Eagle's medium (DMEM), the antibiotics streptomycin and penicillin and different chemicals and analytical grade solvents were procured from HiMedia (Mumbai, India).

\section{Collection and authentication of identification of Ocimum basilicum plant}

The O. basilicum plant used in this investigation was cultivated in the garden area of Bharathidasan University, Tiruchirapalli, Tamil Nadu state, India. Following identification and authentication of the plant (Authentication No. TA001) by Dr. S. John Britto, Director, The Rapinat Herbarium and Centre for Molecular Systematics (St. Joseph's College [Campus], Tiruchirappalli, Tamil Nadu, India), fresh leaves were obtained, shade-dried and powdered. These powdered leaves were extracted independently with aqueous or methanol, followed by final processing.

\section{Preparation of the methanolic and aqueous extracts of O. basilicum leaves}

The extraction procedure followed was that described by Kadan et al. ${ }^{30}$ wherein $30 \mathrm{G}$ of powdered leaves and the solvent $(150 \mathrm{ml})$ were loaded within a Soxhlet apparatus. The resulting solvent underwent evaporation under lowered pressure at $55-60^{\circ} \mathrm{C}$ and then was dried in a vacuum. The residue underwent filtration and concentration to a dry state by vacuum distillation. Both aqueous and methanolic extracts then underwent GC-MS analysis.

\section{Analysis of extracts by gas chromatography-mass spectrometry}

GC-MS analysis (GC/MS-series QP2010, Shimadzu, Tokyo, Japan) was performed using Thermal Desorption (TD) system 20 under defined experimental conditions: RTX-5MS capillary column (30 m x $0.25 \mathrm{~mm}$ and a film thickness of $0.25 \mathrm{~mm}$ ), helium gas (Serving as carrier) at 1.5 $\mathrm{ml} / \mathrm{min}$, a gun temperature of $250^{\circ} \mathrm{C}$, a detector temperature of $290^{\circ} \mathrm{C}$ and a column temperature of $60^{\circ} \mathrm{C}-180^{\circ} \mathrm{C}$ at a rate of $5^{\circ} \mathrm{C} / \mathrm{min}$, followed by $180^{\circ}-280^{\circ} \mathrm{C}$ at $10^{\circ} \mathrm{C} / \mathrm{min}(10 \mathrm{~min})$, a scanning speed of $0.5 \mathrm{scan} / \mathrm{sec}$ of $\mathrm{m} / \mathrm{z} 40$ and 350 and a split ratio of 1:200. The volume injected was $1 \mu \mathrm{l}$. The samples (Dissolved in chloroform) underwent a full run within a range of 50-650 mass-to-charge ratios $(\mathrm{m} / \mathrm{z})$. The mass spectrometer was operated with $70 \mathrm{eV}$ ionization energy. Individual components were identified by mass spectral fragmentation using the NIST Mass 08 spectral library, in addition to retention indices and compared with published data.
Elucidation of possible in vitro antioxidative mechanisms of the Ocimum basilicum extracts

2,2-Diphenyl-1-picrylhydrazyl (DPPH) radical-scavenging assay

DPPH radical-scavenging by the extracts was quantified by a modification of a frequently-used procedure (Details provided in Supplementary Files). ${ }^{31}$ The DPPH radical-scavenging potential for each extract was separately calculated thus:

$$
\text { DPPH scavenging activity }(\%)=\left[\left(\mathrm{A}_{\text {cont }}-\mathrm{A}_{\text {test }}\right)\right] /\left(\mathrm{A}_{\text {cont }}\right) \times 100 \text {, }
$$

$\mathrm{A}_{\text {cont }}$ being absorbance of the control reaction and $\mathrm{A}_{\text {test }}$ being absorbance of the mixture with extract or that of a defined reference solution. The assay was done thrice and DPPH radical-scavenging activity (\%) was plotted against different dilutions of each extract.

\section{Metal chelating assay}

Ferrous ion chelation by each extract was quantified using a modified method of Mathew and Abraham (details in Supplementary Files). ${ }^{32}$ Inhibition (\%) of the ferrozine-Fe ${ }^{2+}$ complex that was formed was calculated per the above-stated formula (DPPH scavenging assay).

\section{Reducing power assay}

This was carried out essentially as stated by Oyaizu (Details in Supplementary Files). ${ }^{33}$ A greater absorbance of the reaction mixture was taken to indicate an increased reducing power.

\section{Superoxide anion radical-scavenging assay}

The superoxide anion radical $\left(\mathrm{O}_{2}^{-{ }^{-}}\right)$-scavenging assay was done per a modified procedure proposed by Rajeshwar et al. ${ }^{34}$ details of which are in the Supplementary Files. Superoxide anion radical-scavenging (\%) was calculated per the above formula (DPPH scavenging assay).

\section{Hydroxyl radical-scavenging assay}

This was done per a previously-described procedure by Halliwell et al. ${ }^{35}$ details of which are in Supplementary Files. The intensity of scavenging activity was determined per the above formula (DPPH scavenging assay).

\section{Culture of Lenticular Epithelial Cells}

Human lenticular epithelial B3 (HLE-B3) cells were a kind gift from Aravind Eye Research Foundation, Madurai, Tamil Nadu, India. HLE-B3 cells were cultured in DMEM supplemented with 20\% Fetal bovine serum (FBS), $45 \mathrm{IU} / \mathrm{mL}$ penicillin and $45 \mathrm{IU} / \mathrm{mL}$ streptomycin at $37^{\circ} \mathrm{C}$ in a humidified $5 \% \mathrm{CO}_{2}$ atmosphere.

\section{Cytotoxicity assay}

Potential cytotoxicity of the $O$. basilicum extract was determined by using 3-4,5-(Dimethyl-thyazol-2-yl)-2,5-diphenyltetrazolium (MTT) (Sigma-Aldrich, St. Louis, MO, USA) as the indicator of cytotoxicity. In brief, HLE-B3 cells were cultured as described earlier, except that these cells were seeded (Density of $5 \times 10^{3}$ cells/well) in 96-well tissue culture plates. To each well, $200 \mu \mathrm{l}$ of the extract were added, yielding concentrations ranging from 10 to $300 \mu \mathrm{g} / \mathrm{ml}$ of medium; the cells were then incubated for $24 \mathrm{~h}$. Dimethyl Sulfoxide (DMSO) was used as a negative control. The cells were treated with $0.5 \mathrm{mg} / \mathrm{mL}$ of the MTT- labelling reagent and incubated at $37^{\circ} \mathrm{C}$ for $1 \mathrm{~h}$. A dark blue formazan product of MTT was extracted by the MTT lysing solution $(40 \mathrm{mM} \mathrm{HCl}$ in isopropyl alcohol) and measured (Absorbance of $570 \mathrm{~nm}$ ) by an automatic ELISA reader (Spectra Max 250; Molecular Devices, Sunnyvale, CA, USA). 
Assessment of the potential of 0 . basilicum leaf

methanolic extract to prevent cataract formation in vitro in lenses surgically removed from eyes of Wistar rats

\section{Removal of lenses from eyes of Wistar rats and culture in DMEM}

All experiments and animal handling in this investigation conformed to Institutional guidelines (Institutional Ethical Committee approval Reference No.: BDU/IAEC/2017/NE/ 30/21.03.2017) and to the principles of the Association for Research in Vision and Ophthalmology Statement for the use of Animals in Research. Wistar rats (Rattus norvegicus; 75-90 g) were first anesthetized using diethyl ether and then underwent sacrifice by cervical dislocation. The lens of each eye was dissected out carefully and then incubated at $37^{\circ} \mathrm{C}$ in $3 \mathrm{ml}$ of DMEM (supplemented with fetal bovine serum [10\%] and sodium bicarbonate $[0.9 \mathrm{~g} / \mathrm{L}])$ in a 12 -well Falcon plastic culture plate placed within an incubator with an atmosphere of $95 \%$ air and $5 \% \mathrm{CO}_{2}$. Streptomycin $(60 \mu \mathrm{g} / \mathrm{ml})$ and penicillin $(60 \mu \mathrm{g} / \mathrm{ml})$ were also added to avoid microbial contamination. After incubation for $2 \mathrm{~h}$, any opaque lenses were removed from the set-up; only lenses exhibiting complete transparency were chosen for subsequent experimental studies. The selected lenses were placed in DMEM and were assigned to 3 groups:

1. In Group I ( $\mathrm{n}=8)$, lenses were kept in DMEM alone (Normal control).

2. In Group II $(\mathrm{n}=8)$, lenses were kept in DMEM that contained only sodium selenite $(100 \mu \mathrm{M}$ selenite/ml DMEM) (Selenite-exposed but untreated).

3. In Group III $(\mathrm{n}=8)$, lenses were kept in DMEM that contained sodium selenite $(100 \mu \mathrm{M}$ selenite/ml DMEM) as well as the (methanolic) extract of $O$. basilicum leaves $(200 \mu \mathrm{g} / \mathrm{ml}$ DMEM) (Seleniteexposed and O. basilicum extract-treated).

\section{Morphological evaluation of lenticular opacification}

All lenses underwent gross examination, with dark grid lines serving as a backdrop. A dissecting microscope was used for magnification. The grades of opacification were:

a) 0: no opacity seen (Grid lines were distinctly visible).

b) +: slight opacity seen (Minimal haziness obscuring grid lines, which were still visible).

c) ++: diffuse opacification of almost the full lens (Moderate haziness obscuring grid lines, which were faintly visible).

d) +++: marked opacification of the full lens (Total haziness obscuring grid lines, which were not visualized at all).

\section{Preparation of lenticular homogenate}

Lenses underwent homogenization in 10-fold their mass of phosphate buffer $(50 \mathrm{mM}, \mathrm{pH} 7.2)$, followed by centrifugation $(12,000 \times \mathrm{g})$ for $15 \mathrm{~min}$ at $4^{\circ} \mathrm{C}$. The supernatant yielded was separated and processed for biochemical analysis. The concentration of protein in each sample was measured per the procedure formulated by Lowry et al. with bovine serum albumin serving as a standard. ${ }^{36}$

\section{Quantitative measurement of concentrations of reduced glutathione (GSH) and malondialdehyde (MDA) GSH}

GSH content (Micromoles/g tissue) in lenticular homogenate was measured by a procedure described by Moron et al. (Procedure in Supplementary Files). ${ }^{37}$

\section{Lipid peroxidation}

The lenticular concentration of MDA, a measure of lipid peroxidation was assayed following the method described by Ohkawa et al. (Procedure in Supplementary Files). ${ }^{38}$

\section{Statistical analysis}

The values are documented as mean \pm the standard deviation of multiple readings. The statistical significance of differences between groups was calculated by One-Way Analysis of Variance (ANOVA) using Statistical Package for Social Sciences (SPSS) software package for Windows, version 21, IBM Corporation, New York, USA. Where one-way ANOVA yielded significant results, post-hoc testing was performed for inter-group comparisons using the least significant difference test. The chi-square test with Yates' correction (GraphPad Prism [Version 6], GraphPad Software Inc., San Diego, California, USA) was used wherever appropriate. Values of $P<0.05$ were deemed statistically significant (Highlighted by distinct symbols in tables and figures).

\section{RESULTS}

Phytoconstituents present in the methanolic extract and the aqueous extract of leaves of the O. basilicum plant were located and analysed. The antioxidative potency of the extracts was also assayed.

\section{GC-MS analysis for phytochemicals in aqueous and} methanolic extracts of $O$. basilicum leaves

Several phytochemicals with bioactivity (Percentage peaks expressed with their retention indices shown in Figures 1a and 1b), which probably

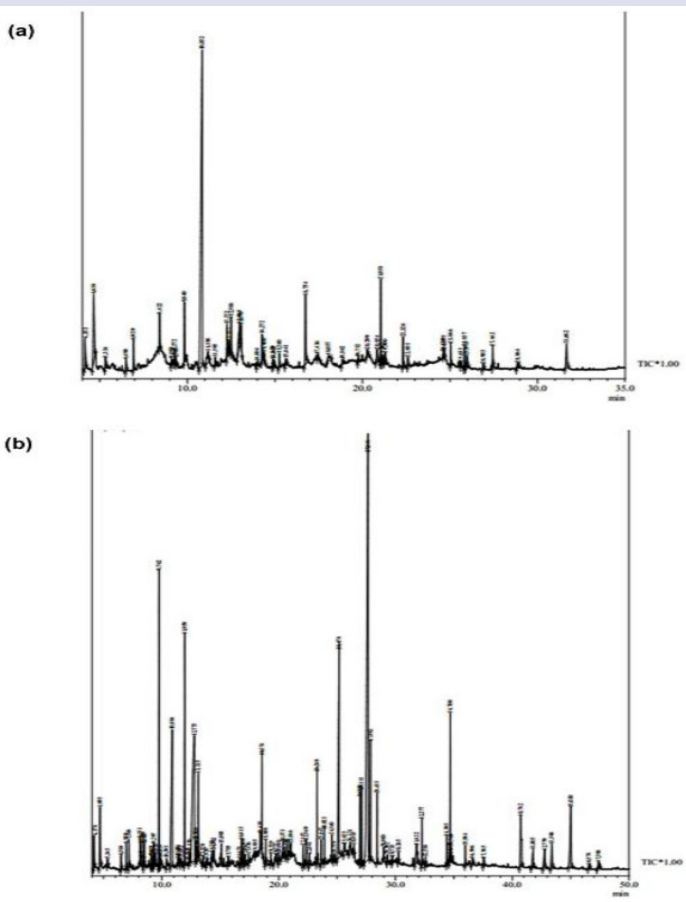

Figure 1: Gas chromatography-mass spectrometry chromatogram. (a) Gas chromatography-mass spectrometry chromatogram of the aqueous extract of leaves of Ocimum basilicum.

(b) Gas chromatography-mass spectrometry chromatogram of the methanolic extract of leaves of Ocimum basilicum.

*Peaks indicate the area percentage of identified phytoconstituents in the extracts of Ocimum basilicum. 
rendered the extracts bioactive, were located and compared with those reported from different medicinal plants (Supplementary data- Tables 1 and 2). By GC-MS analysis, the aqueous extract revealed 47 constituents, of which 19 are documented as biologically-active compounds and 5 are reportedly antioxidants (Supplementary data- Table 1); in the methanolic extract, 89 constituents were present, of which 40 are documented as biologically-active compounds and 19 are reportedly antioxidants (Supplementary data- Table 2). n-hexadecanoic acid (8.10\%), eugenol $(4.89 \%)$ and estragole $(3.68 \%)$ in the methanolic extract and 2-furanmethanol $(2.31 \%)$ in aqueous extract have been designated as major antioxidant components.

\section{In vitro antioxidative potency of extracts of $O$. basilicum leaves}

\section{Scavenging of DPPH radicals by the extracts}

Potential free radical-scavenging by the extracts was assayed by the DPPH method and data generated were compared to results with ascorbic acid standard (Figure 2a). Both extracts and also ascorbic acid, showed significant dose-dependent inhibition of DPPH radicals. However, radical-scavenging by these extracts was inferior to that by ascorbic acid (Figure 2a). Interestingly, $100 \mu \mathrm{g} / \mathrm{ml}$ concentrations of the aqueous and methanolic extracts exhibited radical-scavenging of $77.85 \%$ and $80.43 \%$, respectively $(P<0.05)$ (Figure $2 \mathrm{a})$.

\section{Metal chelating activity of the extract}

The ferrous ion-chelating potential of both extracts was compared with that of ascorbic acid (Figure 3a); the methanolic extract, in a concentration of $100 \mu \mathrm{g} / \mathrm{ml}$, showed a significantly higher chelating percentage $(82.84 \%)$ than that $(72.33 \%)$ shown by $100 \mu \mathrm{g} / \mathrm{ml}$ of the aqueous extract, irrespective of the ferrous ion concentration (Figure 3a).

\section{Reducing power of the extracts}

The reducing power of the $O$. basilicum extracts was contrasted with that of ascorbic acid (Figure 3b); the methanolic extract displayed a reducing power that was superior to that of the aqueous extract and this was found to rise with increasing extract concentrations.

\section{Potential of the extracts to scavenge superoxide anion- radicals}

Even low concentrations $(50 \mu \mathrm{g} / \mathrm{ml})$ of the O. basilicum extracts, showed marked scavenging of superoxide anion radicals (Figure $2 \mathrm{~b}$ ), with the intensity of scavenging by the methanolic extract (81.25\%) exceeding that shown by the aqueous extract (71.52\%) (Figure $2 b$ ).

\section{Scavenging of hydroxyl radicals by extracts}

Inhibition of hydroxyl radical-mediated deoxyribose damage by the O. basilicum extracts was evaluated utilizing the iron (II)-dependent DNA damage assay (Figure 2c). Hydroxyl radical-scavenging activities of $65.5 \%$ (Methanolic extract $50 \mu \mathrm{g} / \mathrm{ml}$ ) and $76.35 \%$ (aqueous extract $50 \mu \mathrm{g} / \mathrm{ml}$ ) were noted (Figure 2c); ascorbic acid, which effectively inhibits hydroxyl radicals, showed $81.39 \%$ scavenging effect (Significantly superior to both extracts) (Figure 2c).

In contrast to the aqueous extract, the methanolic extract possessed a greater number of phytochemicals that have been reported to show antioxidant activity (Supplementary data- Tables 1 and 2) and exhibited superior scavenging of various radicals (DPPH, superoxide anion, hydroxyl) and a greater intensity of ferrous ion-chelating activity. Hence, the methanolic extract alone underwent further assessment for its in-vitro anticataractogenic potency in rat lenses. (a)

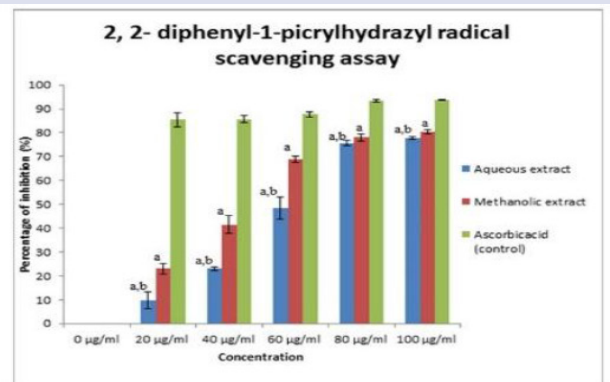

(b)



(c)



Figure 2: Differential scavenging effects of ascorbic acid (Control) and of an aqueous extract and a methanolic extract of leaves of Ocimum basilicum on radicals.

a) Differential scavenging effects on 2, 2-diphenyl-1-picrylhydrazyl (DPPH) radicals; b) Differential scavenging effects on superoxide anion radicals; c) Differential scavenging effects on hydroxyl-anion radicals.

Statistical Analysis

Each value is expressed as mean \pm standard deviation of six determinations. One-way analysis of variance [ANOVA] with post hoc testing (Least significant difference).

aStatistically significant difference $(P<0.05)$ when compared with ascorbic acid (Control) values.

bStatistically significant difference $(P<0.05)$ when compared with methanolic extract values.

\section{Cytotoxicity of the methanolic extract of $O$. basilicum}

In the present investigation, the potential cytotoxicity of the methanolic extract of O. basilicum was tested on HLE-B3 cells (Figure 4a), employing MTT assay. As illustrated in Figure 4b, HLE-B3 cells were exposed to varying concentrations of the extract $(10-300 \mu \mathrm{g} / \mathrm{mL})$ for $24 \mathrm{~h}$. The methanolic extract exhibited negligible cytotoxicity, with an $\mathrm{IC}_{50}$ value of $127 \mu \mathrm{g} / \mathrm{mL}$ at the end of the $24 \mathrm{~h}$ exposure period. There was a decrease in the viability of cells only when exposed to concentrations greater than $300 \mu \mathrm{g} / \mathrm{mL}$ of the extract. 


\section{The potential of the $O$. basilicum leaf methanolic} extract to prevent cataract formation in cultured lenses surgically removed from Wistar rat eyes

\section{Gross morphology of the cultured lenses}

Even after incubation in DMEM alone for $24 \mathrm{~h}$, all 8 (100\%) control lenses did not reveal any opacity (Grade 0 opacification). In contrast, after $24 \mathrm{~h}$ incubation, all eight (100\%) Group II lenses (incubated in DMEM containing sodium selenite) showed marked opacity formation (Grade +++ ). Interestingly, after $24 \mathrm{~h}$ incubation, only one (12.5\%) of eight Group III lenses (which were incubated in DMEM containing sodium selenite and the methanolic extract added simultaneously), showed Grade + opacification, while the other seven (87.5\%) showed Grade 0 (no) opacification (Table 1, Figure 5).

\section{Quantitation of mean levels of GSH and MDA}

The mean lenticular level of GSH in the group of lenses exposed to sodium selenite but not treated, was significantly less than the mean lenticular GSH level in control (Normal) lenses (Table 2). The mean lenticular level of GSH in the group of lenses exposed to selenite and treated with the extract was significantly higher than the mean lenticular GSH level in the untreated group but did not differ significantly compared to mean lenticular level of GSH in the normal control group (Table 2).

Although the mean lenticular MDA concentration in the selenite-exposed, untreated group was significantly greater than the mean lenticular MDA concentrations in the normal control lenses and the selenite-exposed, extract-treated lenses (Table 2), the mean MDA level in extract-treated lenses did not differ significantly from the mean MDA level in control (Normal) group of lenses (Table 2).

\section{DISCUSSION}

Exposure to excessive oxidative stress reportedly leads to lenticular opacification..$^{39}$ Antioxidants may prevent or impede evolution of diseases arising from oxidative stress by raising levels of endogenous antioxidant defences. ${ }^{40}$ Possibly, antioxidative treatment may effectively prevent cataracts and other oxidative stress-related complications. However, different clinical studies have yielded inconsistent results. Ocimum basilicum, commonly called the basil plant, finds application in Unani and Ayurveda medications. Although O. basilicum possesses antioxidant potential, this plant has yet to be screened to detect phytochemicals with antioxidative potency. A plant's medicinal property depends on its phytoconstituents and associated secondary metabolites. ${ }^{41}$ We tried to detect phytoconstituents in aqueous (Figure 1a) and methanolic (Figure 1b) extracts of leaves of $O$. basilicum. While the two extracts exhibited many phytoconstituents, GC-MS analysis suggested that the methanolic extract possessed a greater number of antioxidant compounds than that possessed by the aqueous extract (Supplementary data- Table 1 and 2).

The major constituent detected in the extract, namely $n$-hexadecanoic acid (Area percentage $8.1 \%$ ) (Supplementary data-Table 2), has previously been observed in an extract of Pistia stratiotes leaf ${ }^{42}$ and in Neolamarckia cadamba ${ }^{43}$ leaves is reportedly endowed with antioxidant and antiinflammatory properties. ${ }^{44}$ Eugenol (4.89\%), an additional major constituent (Supplementary data-Table 2), is documented to exhibit antioxidant properties and to reduce free-radical generation within an in-vitro experimental system. ${ }^{45}$ Devendran and Balasubramanian have also reported that an extract of Ocimum sanctum had eugenol as a major constituent. $^{46}$ Yet another major constituent, estragole (3.68 \%) (Supplementary data- Table 2), which was found in an extract of Artemisia dracunculus ${ }^{47}$ is reportedly endowed with antioxidant potential.

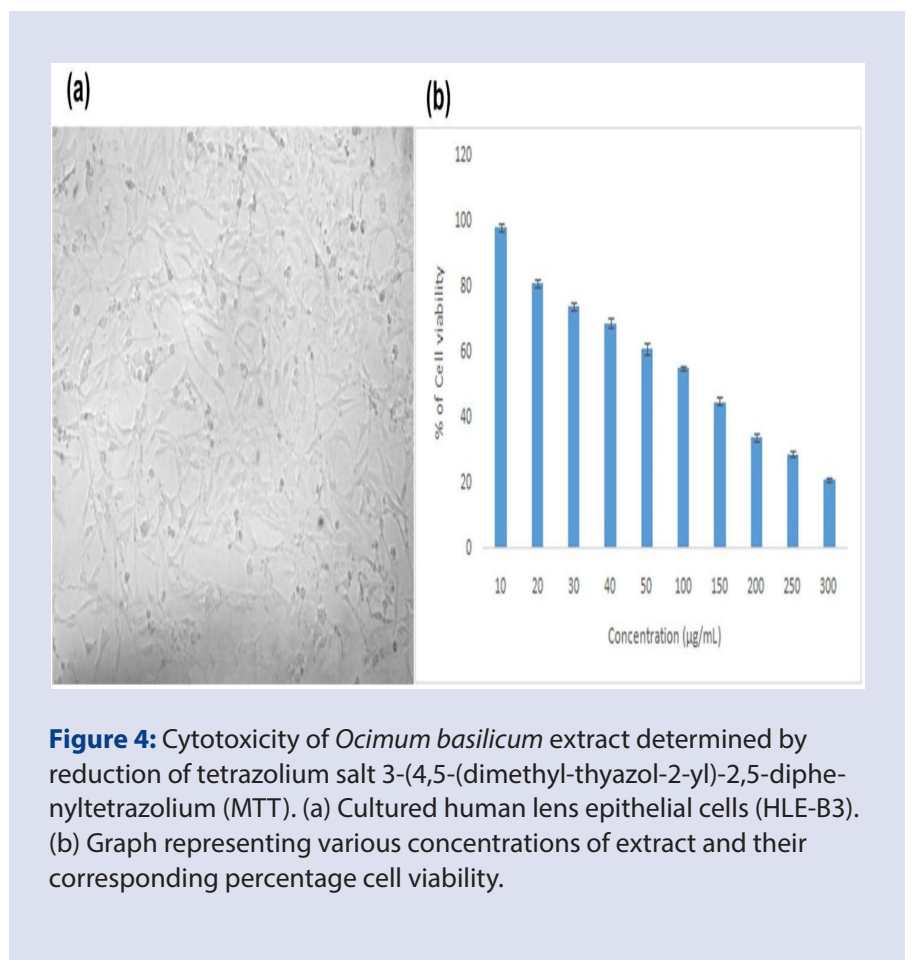

Table 1: Grading of lenticular opacification in Wistar rat lenses incubated for $\mathbf{2 4} \mathrm{h}$ in Dulbecco's modified Eagle's medium (DMEM).

\begin{tabular}{cccc}
\hline $\begin{array}{c}\text { Groups } \\
\text { of lenses } \\
\text { (Incubated in } \\
\text { DMEM)* }\end{array}$ & $\begin{array}{c}\text { Total } \\
\text { number of } \\
\text { lenses }\end{array}$ & $\begin{array}{c}\text { Grades of } \\
\text { opacification** }\end{array}$ & $\begin{array}{c}\text { Number of lenses } \\
\text { with different } \\
\text { grades of lenticular } \\
\text { opacification }\end{array}$ \\
\hline Group I & 8 & 0 & all 8 \\
Group II & 8 & +++ & all 8 \\
Group III & 8 & 0 & 7 of 8 \\
& & + & 1 of 8
\end{tabular}

\section{${ }^{\star}$ Groups of Lenses}

(1) Group I ( $\mathrm{n}=8)$ comprising normal lenses incubated in DMEM alone (Control).

(2) Group II $(\mathrm{n}=8)$ comprising lenses incubated in DMEM containing sodium selenite only (100 $\mu \mathrm{M}$ selenite/ml DMEM) (Selenite-exposed, untreated).

(3) Group III $(n=8)$ comprising lenses incubated in DMEM containing sodium selenite $(100 \mu \mathrm{M}$ selenite/ml DMEM) and the methanolic extract of Ocimum basilicum leaves $(200 \mu \mathrm{g} / \mathrm{ml}$ DMEM) (Selenite-exposed, O. basilicum extracttreated).

\section{${ }^{* *}$ Grades of Opacification}

$0=$ absence of opacification (Gridlines clearly visible);

$+=$ presence of a slight degree of opacification (Minimal clouding of gridlines [Gridlines still visible]).

$++=$ presence of diffuse opacification involving almost the entire lens (Moderate clouding of gridlines [gridlines faintly visible]).

$+++=$ presence of extensive thick opacification involving the entire lens (Total clouding of gridlines [Gridlines not seen at all]).

\section{Statistical Analysis}

Lenticular opacification in Group II vs. that in Group I and in Group III; Yates' chi-square $\left(\chi^{2}\right)$ test [Degree of freedom $\left.=2\right]=9.54 ; p<0.05$. 

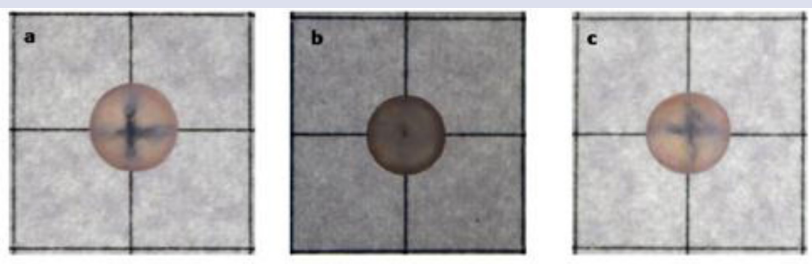

Figure 5: Morphological assessment of lenticular opacification in Wistar rat lenses incubated for $24 \mathrm{~h}$ in Dulbecco's modified Eagle's medium.

a) Group I: Lenses incubated in Dulbecco's modified Eagle's medium (DMEM) alone (Normal control). Grade 0 opacification present (No opacification).

b) Group II: Lenses incubated in DMEM containing sodium selenite only (100 $\mu$ M selenite/ml of DMEM) (Selenite-exposed, untreated). Grade 3 opacification present.

c) Group III: Lenses incubated in DMEM containing sodium selenite (100 $\mu \mathrm{M}$ selenite/ml DMEM) and the methanolic extract of Ocimum basilicum leaves ( $200 \mu \mathrm{g} / \mathrm{ml}$ DMEM) (Selenite- challenged, O. basilicum extract-treated). Grade 1 opacification present.

Table 2: Mean levels of reduced glutathione and of malondialdehyde in Wistar rat lenses incubated for $\mathbf{2 4} \mathrm{h}$ in Dulbecco's modified Eagle's medium (DMEM).

\begin{tabular}{cccc}
\hline \multirow{2}{*}{ Component analysed (unit) } & \multicolumn{3}{c}{ Mean values in lenses * } \\
\cline { 2 - 4 } & Group I & Group II & Group III \\
\hline $\begin{array}{c}\text { Reduced glutathione } \\
\text { ( } \mu \text { mol/gm tissue) }\end{array}$ & $7.09 \pm 0.18$ & $5.07 \pm 0.29^{\mathrm{a}}$ & $6.61 \pm 0.44^{\mathrm{b}}$ \\
$\begin{array}{c}\text { Malondialdehyde } \\
(\mathrm{nmol} / \text { gm tissue) }\end{array}$ & $14.98 \pm 4.92$ & $23.87 \pm 1.89^{\mathrm{a}}$ & $17.21 \pm 1.95^{\mathrm{b}}$ \\
\hline
\end{tabular}

${ }^{\star}$ Groups of Lenses

(1) Group I $(\mathrm{n}=8)$ comprising normal lenses incubated in DMEM alone (Control).

(2) Group II $(\mathrm{n}=8)$ comprising lenses incubated in DMEM containing sodium selenite only (100 $\mu \mathrm{M}$ selenite/ml DMEM) (Selenite-exposed, untreated).

(3) Group III $(\mathrm{n}=8)$ comprising lenses incubated in DMEM containing sodium selenite $(100 \mu \mathrm{M}$ selenite/ml DMEM) and the methanolic extract of Ocimum basilicum leaves (200 $\mu \mathrm{g} / \mathrm{ml}$ DMEM) (Selenite-exposed O. basilicum extract-treated). Statistical Analysis

Values represent mean \pm standard deviation of six determinations; One-way analysis of variance with post-hoc test [Least significant difference].

aStatistically significant difference $(P<0.05)$ when compared with group I or group III values.



The biological activities of phytoconstituents are possibly linked to their antioxidant characteristics. ${ }^{48}$ The DPPH radical is not affected by metals and enzyme inhibition, since it has an unpaired electron, which exhibits a potent absorption maximum at $517 \mathrm{~nm}$ in visible spectroscopy. ${ }^{31,49} \mathrm{We}$ noted good DPPH radical-scavenging potency in both extracts (Figure 3), although the methanolic extract appeared to be more effective than the aqueous extract in this characteristic (Figure 2a).

In the metal-chelating assay, an antioxidant reduces a Fe (III) salt through an electron transfer mechanism. Transition metals, including copper and iron, heighten oxidative stress. The chelation of metal ions can decrease their activity, thereby reducing generation of ROS. ${ }^{50}$ In our (a)



(b)

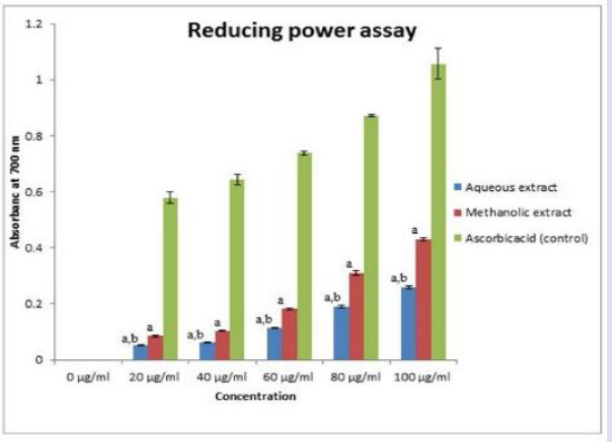

Figure 3: Differential Chelating Effects and Reducing Power of Ascorbic Acid (Control) and of an Aqueous Extract and a Methanolic Extract of Leaves of Ocimum basilicum.

a) Differential chelating effects on ferrous ions; b) Differential reducing power of Ocimum basilicum.

Statistical Analysis

Each value is expressed as mean \pm standard deviation of six determinations.

One-way analysis of variance [ANOVA] with post hoc testing (Least significant difference).

aStatistically significant difference $(P<0.05)$ when compared with ascorbic

acid (Control) values.

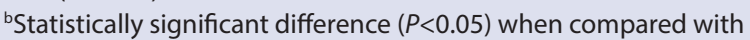
methanolic extract values.

experiments, the $O$. basilicum methanolic extract appeared to be more potent than the aqueous extract in chelating iron (Figure 3a). The reducing power of a compound may point to its antioxidative potential. ${ }^{51} \mathrm{We}$ noted that the reducing power exhibited by both extracts progressively rose proportionate to increasing concentrations of the extracts (Figure $3 b$ ). The higher reducing power of the O. basilicum methanolic extract, compared to the aqueous extract, possibly arose from its greater hydrogendonating capacity.

Superoxide anion $\left(\mathrm{O}^{-\bullet}\right)$, which represents the end product of a oneelectron reduction of oxygen, exhibits toxicity to cellular components, as a consequence of being a precursor of most ROS as well as a mediator in oxidative chain reactions. ${ }^{52}$ Our observations point to the methanolic extract being superior to the aqueous extract in scavenging superoxide anions (Figure $2 \mathrm{~b}$ ). The hydroxyl radical is the most reactive oxygencentered species and may severely damage adjacent biomolecules. ${ }^{53}$ The hydroxyl radical-scavenging assay was used to demonstrate the potency of the extracts versus that of an ascorbic acid standard in inhibiting 
hydroxyl radical-mediated deoxyribose degradation in a $\mathrm{Fe}^{3+}$-EDTA ascorbic acid and $\mathrm{H}_{2} \mathrm{O}_{2}$ reaction mixture (Figure $2 \mathrm{c}$ ). Our data suggest that the methanolic extract is more potent than the aqueous extract in scavenging hydroxyl radicals (Figure 2c).

Similar antioxidative potency has been noted in other plants, including Leucas indica, ${ }^{54}$ Phyllanthus sacidus ${ }^{55}$ and Azima tetracantha. ${ }^{56}$ Previous reports point to positive associations between supplementation with antioxidative compounds and decreased frequency of occurrence and progression of senile cataracts in human ${ }^{57}$ and in selenite cataracts in experimental animals. ${ }^{58}$ This finding prompted us to test the possible efficacy of the methanolic extract in preventing lenticular opacity in selenite challenged rat lenses.

HLE-B3 cells were exposed to varying concentrations of the methanolic extract $(10-300 \mu \mathrm{g} / \mathrm{mL})$ for $24 \mathrm{~h}$ (Figure $4 \mathrm{~b})$. The methanolic extract exhibited negligible cytotoxicity, with an $\mathrm{IC}_{50}$ value of $127 \mu \mathrm{g} / \mathrm{mL}$ at the end of the $24 \mathrm{~h}$ exposure period. There was a decrease in the viability of cells only when exposed to concentrations greater than $300 \mu \mathrm{g} / \mathrm{mL}$ of the extract. The result suggests that the methanolic extract of $O$. basilicum, is not toxic to HLE-B3 cells, thereby ensuring potential application for preventing/retarding cataractogenesis in humans.

As GC-MS analysis yielded a greater number of antioxidant constituents in the methanolic extract, this extract alone was tested for anticataractogenic potential. Gross morphological examination of cultured lenses revealed intense (Grade +++ ) opacification in all eight (100\%) lenses that had been exposed to sodium selenite but not treated. In contrast, seven (87.5\%) of the eight selenite-exposed, O. basilicum methanolic extracttreated lenses (Group III) showed no opacity at all (Grade 0 opacification) after $24 \mathrm{~h}$ incubation, whereas one single lens (12.5\%) manifested minimal opacification (Grade +; Table 1, Figure 5). Thus, the methanolic extract of $O$. basilicum apparently prevented cataract formation in lenses that had been exposed to sodium selenite. Several antioxidant-rich herbal extracts, such as those of Aralia elata, ${ }^{59}$ Emblica officinalis ${ }^{60}$ and of Vaccinium corymbosum, ${ }^{61}$ also exhibit anticataractogenic potential.

In order to gauge the intensity of oxidative stress among the experimental groups of rat lenses, the level of GSH, that serves as a significant first line of defence versus oxidative stress, was assayed. The concentration of MDA, which is often used as a marker of oxidative damage to lipids, was also determined. GSH, an essential tripeptide thiol, is a crucial intracellular and extracellular antioxidant that shields cells against oxidative stress-induced damage. ${ }^{62} \mathrm{~A}$ decreased cellular GSH concentration may affect GSH-dependent enzymes, including glutathione peroxidase, glutathione reductase, glutathione S-transferase and glucose-6-phosphate dehydrogenase, leading to further oxidative damage. ${ }^{63}$ Treatment of the selenite- challenged lenses with the $O$. basilicum extract apparently prevented reduction of lenticular GSH levels, therein possibly contributing to maintenance of lenticular transparency. MDA is, an important aldehyde resulting from membrane lipid peroxidation. ${ }^{38}$ In the present investigation, disruption of membrane lipids was a possible reason for the observed increase in MDA levels in the lenses exposed to selenite but untreated (Group II), in contrast to MDA levels in control (normal) lenses (Group I); this elevated MDA level possibly contributed to severe oxidative damage and lenticular opacification. The observed lowering of the MDA level in O. basilicum extract-treated group of lenses (Group III) suggests that the extract nullified disruption of membrane lipids, thereby preventing opacification of lens.

\section{CONCLUSION}

A methanolic extract of $O$. basilicum has potent antioxidant activity by virtue of its scavenging actions on DPPH, hydroxyl and superoxide radicals, its reducing power on ferric ions and its chelation of ferrous ions. O. basilicum also exhibits great potential to prevent cataract formation in
Wistar rat lenses by reducing the intensity of lipid peroxidation and by enhancing the level of GSH, possibly due to its antioxidant activity. The antioxidant principles identified within the plant extract, such as n-hexadecanoic acid, eugenol and estragole and 2-furanmethanol, all possibly contributed to the observed effects. These experimental results suggest that a methanolic extract of $O$. basilicum can prevent selenite-induced cataract formation in-vitro; further studies are needed to evaluate possible application in the clinical setting.

\section{APPENDIX A}

Supplementary data.

\section{ACKNOWLEDGEMENT}

Financial support rendered by the University Grants Commission-Basic Scientific Research-Faculty Fellowship (UGC-BSR-FF; Grant No. F. $18-1 / 2011$ (BSR) dt.07.10.2014) to the corresponding author is gratefully acknowledged. The instrumentation facility provided by Department of Science and Technology-Fund for Improvement of Science and Technology Infrastructure (DST-FIST)-Level-I (stage-II) (Ref. No. SR/FST/ LSI-647/2015(C) Dt.11.08.2016) of the Department of Animal Science, Bharathidasan University, is also acknowledged.

\section{CONFLICT OF INTEREST}

The authors declare that there are no conflicts of interest.

\section{ABBREVIATIONS}

DMEM: Dulbecco's modified Eagle's medium; MDA: Malondialdehyde; GSH: Reduced glutathione; ROS: Reactive oxygen species; GC-MS: Gas chromatographic-mass spectrometry; DPPH: 2,2-Diphenyl-1-picrylhydrazyl; ANOVA: One-way analysis of variance; SPSS: Statistical Package for Social Sciences.

\section{REFERENCES}

1. Pascolini D, Mariotti SP. Global estimates of visual impairment: 2010. British Journal of Ophthalmol. 2012;96(5):614.

2. Murthy GVS, Gupta SK, John N, Vashist P. Current status of cataract blindness and Vision 2020: The right to sight initiative in India. Indian J Ophthalmol. 2008;56(6):489-94.

3. Choudhary R, Bodakhe SH. Olmesartan, an angiotensin II receptor blocker inhibits the progression of cataract formation in cadmium chloride induced hypertensive albino rats. Life Sci. 2016;167:105-12.

4. Liu C, Lan Q, He W, Nie C, Zhang C, Xu T, et al. Octa-arginine modified lipid emulsions as a potential ocular delivery system for disulfiram: A study of the corneal permeation, transcorneal mechanism and anti-cataract effect. Colloids Surf B Biointerfaces. 2017;160(Supplement C):305-14.

5. Nita M, Grzybowski A. The role of the reactive oxygen species and oxidative stress in the pathomechanism of the age-related ocular diseases and other pathologies of the anterior and posterior eye segments in adults. Oxid Med Cell Longev. 2016.

6. Padgaonkar VA, Lin LR, Leverenz VR, Rinke A, Reddy VN, Giblin FJ. Hyperbaric Oxygen in vivo Accelerates the Loss of Cytoskeletal Proteins and MIP26 in Guinea Pig Lens Nucleus. Exp Eye Res. 1999;68(4):493-505.

7. Johar SRK, Rawal UM, Jain NK, Vasavada AR. Sequential Effects of Ultraviolet Radiation on the Histomorphology, Cell Density and Antioxidative Status of the Lens Epithelium-An in vivo Study. Photochem Photobiol. 2003;78(3):306-11.

8. Biswas S, Harris F, Dennison S, Singh J, Phoenix DA. Calpains: targets of cataract prevention?. Trends Mol Med. 2004;10(2):78-84

9. Varma SD, Kovtun S, Hegde KR. Role of UV Irradiation and Oxidative Stress in Cataract Formation. Medical Prevention by Nutritional Antioxidants and Metabolic Agonists. Eye Contact Lens. 2011;37(4):233-45.

10. Lobo V, Patil A, Phatak A, Chandra N. Free radicals, antioxidants and functional foods: Impact on human health. Pharmacogn Rev. 2010;4(8):118-26.

11. Isai $M$, Elanchezhian $R$, Sakthivel $M$, Chinnakkaruppan $A$, Rajamohan $M$, Jesudasan CN, et al. Anticataractogenic Effect of an Extract of the Oyster Mushroom, Pleurotus ostreatus, in an Experimental Animal Model. Curr Eye Res. 2009;34(4):264-73.

12. Gupta SK, Srivastava S, Trivedi D, Joshi S, Halder N. Ocimum sanctum 
Modulates Selenite-Induced Cataractogenic Changes and Prevents Rat Lens Opacification. Curr Eye Res. 2005;30(7):583-91.

13. Rooban BN, Lija Y, Biju PG, Sasikala V, Sahasranamam V, Abraham A. Vitex negundo attenuates calpain activation and cataractogenesis in selenite models. Exp Eye Res. 2009;88(3):575-82

14. Anitha TS, Annadurai T, Thomas PA, Geraldine P. Prevention of Selenite-Induced Cataractogenesis by an Ethanolic Extract of Cineraria maritima: An Experimental Evaluation of the Traditional Eye Medication. Biol Trace Elem Res. 2011;143(1):425-36

15. Gacche RN, Dhole NA. Aldose reductase inhibitory, anti-cataract and antioxidant potential of selected medicinal plants from the Marathwada region, India. Nat Prod Res. 2011;25(7):760-63.

16. Anbukkarasi M, Thomas PA, Sheu JR, Geraldine P. In vitro antioxidant and anticataractogenic potential of silver nanoparticles biosynthesized using an ethanolic extract of Tabernaemontana divaricata leaves. Biomed Pharmacother 2017;91:467-75.

17. Sundararajan M, Thomas PA, Babyshalini K, Geraldine P. Identification of phytoconstituents and in-vitro evaluation of the putative anticataractogenic effect of an ethanolic root extract of Leucas aspera. Biomed Pharmacother. 2017:85:87-101.

18. Houghton PJ. Synergy and polyvalence: paradigms to explain the activity of herbal products. Evaluation of Herbal Medicinal Products. 2009;85-94.

19. Mazandarani M, Moghaddam MP, Zolfaghari MR, Ghaemi EA, Bayat H. Effects of solvent type on phenolics and flavonoids content and antioxidant activities in Onosma dichroanthum Boiss. J Med Plant Res. 2012;6(28):4481-8.

20. Goli AH, Barzegar M, Sahari MA. Antioxidant activity and total phenolic compounds of pistachio (Pistachia vera) hull extracts. Food Chem. 2005;92(3):521-5.

21. Sun $T$, Ho CT. Antioxidant activities of buckwheat extracts. Food Chem 2005;90(4):743-9.

22. Tohti I, Tursun M, Umar A, Turdi S, Imin H, Moore N. Aqueous extracts of Ocimum basilicum L. (sweet basil) decrease platelet aggregation induced by ADP and thrombin in vitro and rats arterio-venous shunt thrombosis in vivo. Thromb Res. 2006;118(6):733-9.

23. Opalchenova G, Obreshkova D. Comparative studies on the activity of basil an essential oil from Ocimum basilicum L. against multidrug resistant clinica isolates of the genera Staphylococcus, Enterococcus and Pseudomonas by using different test methods. J Microbiol Methods. 2003;54(1):105-10.

24. Khan I, Ahmad K, Khalil AT, Khan J, Khan YA, Saqib MS, et al. Evaluation of antileishmanial, antibacterial and brine shrimp cytotoxic potential of crude methanolic extract of Herb Ocimum basilicum (Lamiacea). J Tradit Chin Med. 2015;35(3):316-22

25. Harnafi H, Aziz M, Amrani S. Sweet basil (Ocimum basilicum L.) improves lipid metabolism in hypercholesterolemic rats. Eur E J Clin Nutr Metab. 2009;4(4):e181-e186.

26. Rodrigues LB, Oliveira BPBMA, Cesário FRAS, Ferreira ECF, DeAlbuquerque TR, Martins FMN, et al. Anti-inflammatory and antiedematogenic activity of the Ocimum basilicum essential oil and its main compound estragole: in vivo mouse models. Chem Biol Interact. 2016;257:14-25.

27. Chaudhary S, Semwal A, Kumar H, Verma HC, Kumar A. In-vivo study for antihyperglycemic potential of aqueous extract of Basil seeds (Ocimum basilicum Linn) and its influence on biochemical parameters, serum electrolytes and haematological indices. Biomed Pharmacother. 2016;84:2008-13.

28. Srivastava S, Adholeya A, Conlan XA, Cahill DM. Acidic Potassium Permanganate Chemiluminescence for the Determination of Antioxidant Potential in Three Cultivars of Ocimum basilicum. Plant Foods Hum Nutr. 2016;71(1):72-80.

29. Kavoosi G, Amirghofran Z. Chemical composition, radical scavenging and anti-oxidant capacity of Ocimum basilicum essential oil. J Essential Oil Res. 2017;29(2):189-99

30. Kadan S, Saad B, Sasson Y, Zaid H. In vitro evaluation of anti-diabetic activity and cytotoxicity of chemically analysed Ocimum basilicum extracts. Food Chem. 2016;196:1066-74.

31. Brand-Williams W, Cuvelier ME, Berset C. Use of a free radical method to evaluate antioxidant activity. LWT - Food Science and Technology. 1995;28(1):25-30.

32. Mathew S, Abraham TE. In vitro antioxidant activity and scavenging effects of Cinnamomum verum leaf extract assayed by different methodologies. Food Chem Toxicol. 2006;44(2):198-206.

33. Oyaizu M. Studies on products of browning reaction: Antioxidative activity of products of browning reaction prepared from glucosamine. Japanese Journa of Nutrition. 1986;44(6):307-15

34. Rajeshwar Y, Senthil KGP, Gupta M, Upal KM. Studies on in vitro antioxidant activities of methanol extract of Mucuna pruriens (fabaceae) seeds. European Bulletin of Drug Research. 2005;13(1):31-9.

35. Halliwell B, Gutteridge JMC, Arnoma OL. The deoxyribose method: A simple test tube assay for the determination of rate constant for reaction of hydroxyl radical. Anal Biochem. 1987;165(1):215-9.

36. Lowry $\mathrm{OH}$, Rosebrough NJ, Farr AL, Randall RJ. Protein measurement with the Folin phenol reagent. J Biol Chem. 1951;193(1):265-75.

37. Moron MS, Depierre JW, Mannervik B. Levels of glutathione, glutathione reductase and glutathione-S-transferase activities in rat lung and liver. Biochimica et Biophysica Acta. 1979;582(1):67-78.
38. Ohkawa H, Ohishi N, Yagi K. Assay for lipid peroxides in animal tissues by thiobarbituric acid reaction. Anal Biochem. 1979;95(2):351-8.

39. Vinson JA. Oxidative stress in cataracts. Pathophysiology. 2006;13(3):151-62

40. Thébault $\mathrm{S}$. Potential mechanisms behind the antioxidant actions of prolactin in the retina. Exp Eye Res. 2017;160 (Supplement C):56-61.

41. Mohammedi Z, Atik F. Impact of solvent extraction type on total polyphenols content and biological activity from Tamarix aphylla (L.) karst. Int J Pharma Bio Sci. $2011 ; 2(1): 609-15$.

42. Tyagi T, Agarwal M. Phytochemical screening and GC-MS analysis of bioactive constituents in the ethanolic extract of Pistia stratiotes L. and Eichhornia crassipes (Mart.) solms. J Pharmacognosy and Phytochemistry 2017;6(1):195-206.

43. Zayed MZ, Ahmad FB, Ho W, Pang S. GC-MS analysis of phytochemical constituents in leaf extracts of Neolamarckia cadamba (Rubiaceae) from Malaysia International Journal of Pharmacy and Pharmaceutical Sciences. 2014;6(9):123-7.

44. Aparna V, Dileep KV, Mandal PK, Karthe P, Sadasivan C, Haridas M. Anti-inflammatory property of n-hexadecanoic acid: structural evidence and kinetic assessment. Chem Biol Drug Des. 2012;80(3):434-9.

45. Nagababu E, Rifkind JM, Boindala S, Nakka L. Assessment of antioxidant activity of eugenol in vitro and in vivo. Methods Mol Biol. 2010;610:165-80.

46. Devendran G, Balasubramanian U. Qualitative phytochemical screening and GC-MS analysis of Ocimum sanctum L. leaves. Asian Journal of Plant Science and Research. 2011;1(4):44-8.

47. Rajabian A, Khayyat MH, Emami SA, Tayarani-Najaran Z, Oskooie RR, Asili J. Phytochemical evaluation and antioxidant activity of essential oil and aqueous and organic extracts of Artemisia dracunculus. Jundishapur J Nat Pharm Prod. 2017;12(1):1-9

48. Zhang YJ, Gan RY, Li S, ZhouY, Li AN, Xu DP, et al. Antioxidant Phytochemicals for the Prevention and Treatment of Chronic Diseases. Molecules. 2015;20(12):21138-56.

49. Trombino S, Cassano R, Ferrarelli T, Leta S, Puoci F, Picci N. Preparation, Charac terization and Efficacy Evaluation of Synthetic Biocompatible Polymers Linking Natural Antioxidants. Molecules. 2012;17(11):12734-45

50. Lü JM, Lin PH, Yao Q, Chen C. Chemical and molecular mechanisms of antioxidants: experimental approaches and model systems. J Cell Mol Med 2010;14(4):840-60.

51. Hsu B, Coupar IM, Ng K. Antioxidant activity of hot water extract from the fruit of the Doum palm, Hyphaene thebaica. Food Chem. 2006;98(2):317-28.

52. Turrens JF. Mitochondrial formation of reactive oxygen species. J Physiol 2003;552(2):335-44

53. Pavithra K, Vadivukkarasi S. Evaluation of free radical scavenging activity of various extracts of leaves from Kedrostis foetidissima (Jacq.) Cogn. Food Science and Human Wellness. 2015;4(1):42-6.

54. Ramani R, Sudini S, Boddupalli BM, Anisetti RN. Antioxidant, free radical scavenging and in vitro cytotoxic studies of ethanolic extract of Leucas indica va lavandulifolia and Leucas indica var nagalapuramiana. Asian Pac J Trop Biomed. 2012;2(3Supplement):S1637-42.

55. Chakraborty R, Biplab D, Devanna N, Sen S. Antiinflammatory, antinociceptive and antioxidant activities of Phyllanthus acidus L. extracts. Asian Pac J Trop Biomed. 2012;2(2 Supplement):S953-61.

56. Sunil C, Duraipandiyan V, Ignacimuthu S, Al-Dhabi NA. Antioxidant, free radical scavenging and liver protective effects of friedelin isolated from Azima tetracantha Lam. leaves. Food Chem. 2013;139(1):860-5

57. Brown L, Rimm EB, Seddon JM, Giovannucci EL, Chasan-Taber L, Spiegelman $\mathrm{D}$, et al. A prospective study of carotenoid intake and risk of cataract extraction in US men. Am J Clin Nutr. 1999;70(4):517-24.

58. Padmaja S, Raju TN. Antioxidant effect of curcumin in selenium induced cataract of Wistar rats. Indian J Exp Biol. 2004;42:601-3.

59. Chung YS, Choi YH, Lee SJ, Choi Sa, Lee Jh, Kim H, et al. Water extract of Aralia elata prevents cataractogenesis in vitro and in vivo. J Ethnopharmacol. 2005:101(1):49-54

60. Kavitha NN, Patel K, Gandhi T. Effect of aqueous extract of Embelica officinalis on selenite induced cataract in rats. Iran J Pharm Res.2010;9(2):147-52.

61. Ferlemi AV, Makri OE, Mermigki PG, Lamari FN, Georgakopoulos CD. Quercetin glycosides and chlorogenic acid in highbush blueberry leaf decoction prevent cataractogenesis in vivo and in vitro: Investigation of the effect on calpains, antioxidant and metal chelating properties. Exp Eye Res. 2016;145:258-68.

62. Rahman I, MacNee W. Lung glutathione and oxidative stress: implications in cigarette smoke-induced airway disease. Am J Physiol Lung Cell Mol Physiol. 1999:277(6):L1067-88.

63. Arivazhagan P, Ramanathan K, Panneerselvam C. Effect of DLalpha- lipoic acid on glutathione metabolic enzymes in aged rats. Exp Gerontol. 2001;37:81-7. 
GRAPHICAL ABSTRACT

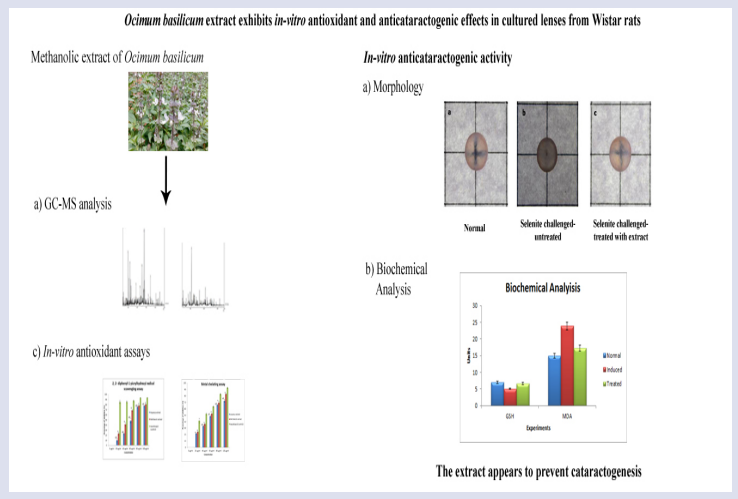

\section{SUMMARY}

- The current study sought to identify bioactive constituents present in the aqueous and methanolic extracts of $O$. basilicum leaves by using gas chromatography-mass spectrometry analysis and to elucidate various antioxidant characteristics.

- The results suggest that the methanolic extract of $O$. basilicum leaf could serve as a better source of antioxidants than the aqueous extract.

- The results suggest that the $O$. basilicum leaf methanolic extract retards selenite-induced cataractogenesis by preventing or dampening selenite-induced free radical formation in lenticular cells.

Cite this article: Anand T, Sundararajan M, Anbukkarasi M, Thomas PA, Geraldine P. A Methanolic Extract of Ocimum basilicum Exhibits Antioxidant Effects and Prevents Selenite-induced Cataract Formation in Cultured Lenses of Wistar Rats. Pharmacog J. 2019;11(3):496-504. 